\title{
Inhibition of chemotherapy-induced apoptosis of testicular cells by squid ink polysaccharide
}

\author{
YI-PENG GU $^{1,2}$, XIAO-MEI YANG ${ }^{1}$, ZHEN-HUA DUAN ${ }^{1}$, PING LUO ${ }^{2}$, JIANG-HUA SHANG ${ }^{3}$, \\ WEI XIAO ${ }^{2}$, YE-XING TAO ${ }^{2}$, DA-YAN ZHANG ${ }^{2}$, YUN-BO ZHANG ${ }^{2}$ and HUA-ZHONG LIU ${ }^{2}$ \\ ${ }^{1}$ Institute of Food Research, Hezhou University, Hezhou, Guangxi 542899; ${ }^{2}$ Department of \\ Applied Chemistry, College of Chemistry and Environment, Guangdong Ocean University, Zhanjiang, Guangdong 524088; \\ ${ }^{3}$ Guangxi Buffalo Research Institute, Chinese Academy of Agricultural Sciences, Nanning, Guangxi 530001, P.R. China
}

Received October 14, 2015; Accepted November 10, 2016

DOI: $10.3892 / e t m .2017 .5342$

\begin{abstract}
The aim of this study was to determine the mechanisms driving the protective effects of squid ink polysaccharide (SIP) against cyclophosphamide (CP)-induced testicular damage, focusing on germ cells. In the testes of mice exposed to CP and/or SIP, the present study examined the levels of reactive oxygen species (ROS) and malondialdehyde, activity of superoxide dismutase levels, protein expression levels of B-cell lymphoma 2 ( $\mathrm{Bcl} 2), \mathrm{Bcl} 2$-associated $\mathrm{X}$ protein (Bax), and total Caspase 3, activation of p-p38 and p-Akt proteins, and tissue morphology. The findings indicated that CP induced ROS production and oxidative stress, resulting in testicular damage. However, under administration of SIP, oxidative stress was impaired and the testicular toxicity induced by CP was weakened, which implied that SIP may have an important role in preventing chemotherapeutic damage to the male reproductive system via promoting antioxidant ability. Furthermore, the altered expression levels, including the upregulation of Bax and Caspase 3, downregulation of $\mathrm{Bcl}-2$ and the increased $\mathrm{Bax} / \mathrm{Bcl}-2$ ratio, indicated that apoptosis occurred in $\mathrm{CP}$ exposed testes of mice; however, the alterations were reversed in mice treated with SIP. Moreover, in CP-exposed testes, $\mathrm{p} 38$ and Akt proteins were significantly phosphorylated $(\mathrm{P}<0.05)$, whereas in the testes of mice co-treated with SIP and $\mathrm{CP}$, phosphorylation of the two proteins was inhibited, demonstrating that the two signalling pathways participated in the regulative processes of the deleterious effects caused by $\mathrm{CP}$, and the preventive effects SIP mediated.
\end{abstract}

Correspondence to: Dr Hua-Zhong Liu, Department of Applied Chemistry, College of Chemistry and Environment, Guangdong Ocean University, 1 Sea Road, Zhanjiang, Guangdong 524088, P.R. China

E-mail: liuhzbs@163.com

Key words: squid ink polysaccharide, cyclophosphamide, testicular germ cells, apoptosis

\section{Introduction}

Cyclophosphamide (CP) exhibits positive therapeutic effects in clinical practice; however, it also causes undesirable harm to normal organs and tissues, such as the testes (1). Previous studies (2-4) have indicated that a large number of free radicals and oxidation products are produced in mice after intraperitoneal injection of $\mathrm{CP}$, which may cause testicular oxidative stress resulting in DNA double-strand breaks and germ cell apoptosis. Intracellular accumulation of excess reactive oxygen species (ROS) can induce apoptosis, resulting in programmed cell death (5). Apoptosis, a mode of programmed cell death, has important roles in cell growth, differentiation and development, and acts as an effective way to induce tumor cell death. Typically, apoptosis is targeted in cancer treatment as an anti-tumor mechanism $(6,7)$. The specific mechanisms involved in apoptosis are yet to be fully understood. The majority of studies suggest that multiple mediators of cell damage, which are triggered by adverse exogenous factors, are closely related to apoptotic cells, including oxygen free radicals, radiation and chemotherapy (8-10).

Squid ink polysaccharide (SIP), a natural marine product, is considered to be a potentially effective, non-toxic, broad-spectrumcy to protective agent due to its anti-oxidant (1), anti-tumor (11) and anti-chemotherapy $(1,12-16)$ functions. SIP has been identified as a type of glycosaminoglycan, with a unique structure: [3GlcA $\beta 1-4($ GalNAc $\alpha 1-3)-F u c \alpha 1]_{\mathrm{n}}(17)$. In previous studies, SIP alleviated toxicity of the chemotherapeutic drug, $\mathrm{CP}$, on the heart, liver, spleen, lung, kidney and intestines $(12-16,18)$. There is also evidence of the protective effect of SIP on the male reproductive system. In a previous study, SIP effectively reduced testicular pathological damage caused by $\mathrm{CP}$ in mice, thus increasing testicular weight and sperm quantity, reducing sperm deformity rates, improving testis iconic enzyme activity and redox homeostasis, and maintaining natural hormone levels in serum and testes (1). Although the preventative effects of SIP towards CP-induced damage of testes and apoptosis in murine germ cells have been identified (10), its regulative processes remain unclear. To elucidate the preventive mechanisms of SIP on the testes of mice exposed to $\mathrm{CP}$, apoptosis of testicular germ cells in mice treated with CP and SIP was investigated in the present study. 


\section{Materials and methods}

Preparation of SIP. Fresh squid (Sepia esculenta) were caught from the East coast of Beibu Gulf. Their ink sacs were removed by the fishermen and stored at $-70^{\circ} \mathrm{C}$ in an ultra-low temperature freezer. SIP was prepared with a slightly modified method as described by Chen et al (17). Briefly, the frozen squid ink was thawed at $4^{\circ} \mathrm{C}$, diluted with an equal volume of PBS (0.01 mol/l; pH 7.4) and treated by sonication in an ice bath. Following storage at $4^{\circ} \mathrm{C}$ for $>8 \mathrm{~h}$, the mixture was centrifuged $(7,155 \mathrm{xg})$ at $4^{\circ} \mathrm{C}$ for $50 \mathrm{~min}$. The supernatant was collected and hydrolyzed with papain $(1.5 \%)$ at $50^{\circ} \mathrm{C}$ for $90 \mathrm{~min}$ and heated in boiling water to denature the protease. Proteins in the treated supernatant were removed by the Sevag method (19). The aqueous phase was mixed with four volumes of ethanol to precipitate the polysaccharides. Crude polysaccharides were obtained from the precipitate and subsequently separated into three fractions by DEAE- 52 cellulose column chromatography (GE Healthcare Life Sciences, Chalfont, UK). The first fraction, in which the peak area was far larger than the others, was collected, dialyzed, concentrated, and further purified in a Sephacryl S-300HR column (GE Healthcare Life Sciences). One elution peak was obtained from a S-300HR column and the fraction from that peak was named SIP. The collected SIP was dialyzed, concentrated, freeze-dried and stored at $-20^{\circ} \mathrm{C}$.

Animals and experimental design. A total of 40 sexually mature male Kunming mice (weighing $25 \pm 2 \mathrm{~g}$ ), aged 6 weeks, were purchased from the Experimental Animal Centre of Guangxi Medical University (Nanning, China; SCXK(Gui) 2009-002). Mice were adaptively domesticated for one week under the following constant experimental conditions: Relative humidity, $55 \pm 5 \%$; temperature, $22 \pm 2^{\circ} \mathrm{C}$; quasi-diurnal cycle of $12 \mathrm{~h}$ light and $12 \mathrm{~h}$ darkness; and ad libitum access to food and water.

A total of 40 mice were randomly divided into four equal experimental groups: Control group (CON; orally administered and abdominally injected with normal saline); CP-treated group (CP; orally administered normal saline and abdominally injected with CP in normal saline); SIP-treated group (SIP; orally administered SIP and abdominally injected with normal saline); and a co-treated group (SIP+CP; orally administered SIP and abdominally injected with $\mathrm{CP}$ in normal saline). SIP was administered once a day for two weeks with $80 \mathrm{mg} / \mathrm{kg}$ body weight chosen as an optimal concentration of SIP from our previous studies $(1,20)$. CP was intraperitoneally injected once on the 7th day of SIP or saline administration; $120 \mathrm{mg} / \mathrm{kg}$ body weight was chosen as the dose to obtain optimal effects in this model, since a large dose may result in testicular damage due to increased cellular sensitivity when exposed to high doses of $\mathrm{CP}(21,22)$. Following treatment, all mice were sacrificed by dislocation of cervical vertebra at $24 \mathrm{~h}$ after the last administration. Bilateral testes were collected, rapidly cleared of surrounding fat and connective tissue and stored at $-70^{\circ} \mathrm{C}$.

Detection of testicular oxidative stress level. Samples were homogenised quickly in ice-cold PBS at $4^{\circ} \mathrm{C}$. The homogenate was centrifuged $2,000 \mathrm{x}$ g for $10 \mathrm{~min}$ at $4^{\circ} \mathrm{C}$. The supernatant was determined by measuring the activity of superoxide dismutase (SOD), contents of malondialdehyde (MDA) and reactive oxygen species (ROS) with detection kits according to manufacturers' protocols. SOD assay kit (Hydroxylamine method, cat. no. A001-1), ROS assay kit (Dichlorofluorescein method, cat. no. E004) and MDA assay kit (TBA method, cat. no. A003-1) were purchased from Nanjing Jiancheng Bioengineering Institute (Nanjing, China).

Transmission electron microscopy detection. Testes were fixed with 5\% glutaraldehyde in PBS followed by post-fixation with $1 \%$ osmic acid formulated with PBS. Following washing three times with PBS, the tissue was dehydrated with ethanol and acetone, embedded in Epon812 and sectioned into 60-70 nm with an ultra-microtome. Sections were stained with $2 \%$ uranyl acetate and lead citrate and the ultra-structure of testicular germ cells was observed by transmission electron microscopy.

Terminal-deoxynucleoitidyl transferase-mediated nick-end labelling (TUNEL) assay. TUNEL assay was performed according to the manufacturer's instructions, Situ TUNEL apoptosis detection kit was purchased from Nanjing Jiancheng Bioengineering Institute (Nanjing, China). Procedure was as follows: De-waxed and hydrated testes paraffin sections were washed three times with PBS and incubated in DNase-free Proteinase $\mathrm{K}$ for $30 \mathrm{~min}$ at $37^{\circ} \mathrm{C}$. Following washing, sections were immersed in methanol solution at room temperature for $5 \mathrm{~min}$, the excess liquid was removed with filter paper and the sample was incubated in TdT enzyme reaction solution for $60 \mathrm{~min}$ at $37^{\circ} \mathrm{C}$ prior to washing with PBS. Excess liquid was removed with filter paper and the sections were incubated in Streptavidin-HRP solution at $37^{\circ} \mathrm{C}$ for $30 \mathrm{~min}$ in the dark. Following washing, each section was stained with 3,3'-diaminobenzidinesolution at room temperature for $10 \mathrm{~min}$ and washed with PBS. The sections were observed under an optical microscope (magnification, x200), and brown particles were deemed to be indicative of apoptosis-positive cells. The number of positive cells per 100 germ cells was calculated as the positive rate of apoptosis, which indicated the percentage of apoptosis-positive cells in the total cell count.

Western blot analysis. Western blot was used to assess the levels of B-cell lymphoma 2 (Bcl2), Bcl2-associated X (Bax), Caspase 3, LC3B, Beclin-1, phospho-p38, phospho-Akt and $\beta$-actin. Samples were homogenized in a $1 \mathrm{ml} / 0.1 \mathrm{~g}$ tissue RIPA lysis buffer with $1 \mathrm{mM}$ phenylmethyylsulfonyl fluoride (Beyotime Institute of Biotechnology, Shanghai, China) in a homogenizer. Following lysis for $20 \mathrm{~min}$ on ice and centrifugation at $10,000 \times \mathrm{g}$ for $3 \mathrm{~min}$ at $4^{\circ} \mathrm{C}$, the protein content was determined using the Enhanced BCA Protein Assay kit (Beyotime Institute of Biotechnology). All the resulting extracts were adjusted to the same concentration and electrophoresed on a $10 \%$ SDS-PAGE. The loading quantity was $40 \mu \mathrm{g}$. The separated proteins were then transferred onto polyvinylidene difluoride membranes. The membranes were blocked by incubation with a phosphate-buffered saline and Tween-20 (PBST) buffer $(0.05 \%$ Tween- $20,100 \mathrm{mM} \mathrm{NaCl}, 10 \mathrm{mM}$ Tris-HCl $\mathrm{pH}$ 7.4), containing $10 \%$ nonfat dry milk for $2 \mathrm{~h}$, then incubated with one of the following antibodies: Caspase 3 rabbit polyclonal antibody (cat. no. 19677-1-AP, Proteintech Group, Inc., Chicago, 
IL, USA), Bax rabbit polyclonal antibody (cat. no. 50599-2-Ig; Proteintech Group, Inc.), Bcl-2 rabbit polyclonal antibody (cat. no. 12789-1-AP; Proteintech Group, Inc.), Phospho-p38 MAPK rabbit monoclonal antibody (cat. no. 4092S; Cell Signaling Technology,Inc., Danvers, MA,USA), Akt-phospho-S473 mouse monoclonal antibody (cat. no. 66444-1-Ig; Proteintech Group, Inc.), beta actin rabbit polyclonal antibody (cat. no. 20536-1-AP; Proteintech Group, Inc.), beta actin mouse monoclonal antibody (cat. no. 60008-1-Ig; Proteintech Group, Inc.), at concentrations of 1:2,000. They were then washed three times with $0.05 \%$ Tween-20 in PBST for 5 min by slowly shaking and finally incubated for $2 \mathrm{~h}$ with anti-rabbit $\operatorname{IgG}(\mathrm{H}+\mathrm{L})$ secondary antibody (KPL, Inc., Gathersburg, MD, USA) at concentrations of 1:2,000. The membranes were washed with PBST and the proteins were detected with a substrate super ECL Plus solution (Applygen Technologies Inc., Beijing, China). All these steps were carried out at room temperature. Densitometric analysis of digitalized images was done with the ImageJ software (National Institutes of Health, Bethesda, MD, USA).

Statistical analysis. All experimental data were presented as mean \pm standard deviation. Data were analysed using JMP 7.0.2 (SAS Institute Inc., Cary, NC, USA). One-way analysis of variance and the post-hoc Tukey's honest significant difference test were used to evaluate differences between groups. $\mathrm{P}<0.05$ was considered to indicate a statistically significant difference.

\section{Results}

SIP inhibits $C P$-induced oxidative stress in mice testes. ROS levels, SOD activity and MDA content in testes are shown in Table I. Significant increases in ROS level and MDA content, and a reduction in SOD activity were observed in mice exposed to $\mathrm{CP}(\mathrm{P}<0.05)$. After SIP treatment, SOD activity of CP-treated mice was obviously higher $(\mathrm{P}<0.05)$, ROS levels and MDA content were also greatly reduced $(\mathrm{P}<0.05)$. To sum up, its preventive effects on the testes of CP-treated mice were found by evaluating the three indicators, which implied marked inhibition of oxidative stress in CP-exposed testes following treatment with SIP.

SIP prevents $C P$-induced damage of histological structures in mice testes. As demonstrated in Fig. 1, testicular tissues of vehicle- and SIP-treated mice exhibited normal histological structures, including the correct epithelial thickness of the seminiferous tubule, plentiful layers of cells, compactness and regularity of spermatogenic cells, as well as rich capillaries inthe periphery of the seminiferous tubule. However, the histological structure of the CP-treated group showed reduced epithelial thickness of the seminiferous tubule and fewer layers of cells. Furthermore, spermatogenic cell counts decreased and their structures were disarranged; in addition, few capillaries were observed in the enlarged space between seminiferous tubules. In the group co-treated with SIP and CP, histological structure was visibly better than that of CP-treated mice, as indicated by comprehensive assessment of the aforementioned parameters.

SIP prevents CP-induced apoptosis of testicular germ cells. TUNEL was used to detect DNA strand breaks generated
Table I. ROS level, MDA content and SOD activity in testes.

\begin{tabular}{llcl}
\hline Group & $\begin{array}{c}\text { ROS } \\
(\text { a.u./mg })\end{array}$ & $\begin{array}{c}\text { SOD } \\
(\mathrm{U} / \mathrm{mg})\end{array}$ & $\begin{array}{c}\text { MDA } \\
(\mathrm{nmol} / \mathrm{m})\end{array}$ \\
\hline CON & $32.39 \pm 5.76$ & $101.17 \pm 5.34^{\mathrm{a}}$ & $11.99 \pm 3.80$ \\
CP & $46.74 \pm 5.37^{\mathrm{a}, \mathrm{b}}$ & $76.48 \pm 5.70$ & $21.90 \pm 2.36^{\mathrm{a}, \mathrm{b}}$ \\
SIP+CP & $31.42 \pm 5.35$ & $99.62 \pm 4.51^{\mathrm{b}}$ & $12.10 \pm 3.89$ \\
SIP & $29.87 \pm 4.84$ & $96.95 \pm 6.49$ & $12.21 \pm 4.41$ \\
\hline
\end{tabular}

Mice were orally administered $80 \mathrm{mg} / \mathrm{kg}$ SIP once a day for two weeks (SIP+CP and SIP, respectively). After $2 \mathrm{~h}$ on the 7th day of SIP treatment, mice were injected with $120 \mathrm{mg} / \mathrm{kg}$ cyclophosphamide (CP and SIP+CP, respectively). Control mice were orally administered and/or injected with saline. ${ }^{a} \mathrm{P}<0.05$ vs. $\mathrm{CON}$. ${ }^{\mathrm{b}} \mathrm{P}<0.05$ vs. $\mathrm{CP}$. ROS, reactive oxygen species; SOD, superoxide dismutase; MDA, malondialdehyde; $\mathrm{CON}$, control mice; $\mathrm{CP}, \mathrm{CP}$-treated mice; $\mathrm{SIP}+\mathrm{CP}$, mice treated with squid ink polysaccharide and CP; SIP, squid ink polysaccharide-treated mice.

during early-stage apoptosis and to observe the direct location of apoptosis (Fig. 2). In the control group, few apoptotic cells were present in the cell layers of spermatogonia. CP-treated mice exhibited a large number of apoptotic cells distributed predominantly in the spermatogonial layer, and the positive rate of apoptosis was significantly increased compared with the other groups $(\mathrm{P}<0.05)$. Similar to the control mice, minimal evidence of apoptosis was observed in the cell layers of the SIP-treated mice. Compared with the CP-treated mice, mice co-treated with SIP and CP exhibited lower levels of apoptosis in each cell layer. These results demonstrated that the positive rate of apoptosis was significantly decreased by SIP $(\mathrm{P}<0.05)$.

Effect of SIP on the CP-mediated expression of caspase-3, Bcl-2 and Bax genes, and phosphorylation of p38 and Akt proteins. As shown in Fig. 3, CP upregulated Caspase-3 protein expression $(\mathrm{P}<0.01)$ and improved photophosphorylation of p38 $(\mathrm{P}<0.05)$ and Akt proteins $(\mathrm{P}<0.01)$ in mice testes. Bcl-2 protein expression was significantly decreased by $\mathrm{CP}(\mathrm{P}<0.01)$ and the $\mathrm{Bax} / \mathrm{Bcl}-2$ ratio was significantly increased $(\mathrm{P}<0.01)$. Following administration of SIP, testes of CP-exposed mice showed a significant reduction of photophosphorylation of p38 protein $(\mathrm{P}<0.01)$ and a significant decrease in the protein expression of Caspase-3 $(\mathrm{P}<0.05)$, while the expression level of the $\mathrm{Bcl}-2$ gene was significantly increased $(\mathrm{P}<0.01)$. A significant decrease in $\mathrm{Bax} / \mathrm{Bcl}-2$ ratio was also observed in the SIP + CP group compared with the CP group $(\mathrm{P}<0.05)$. Compared with the $\mathrm{CP}$-treated group, the protein expression of p-Akt in mice co-treated with SIP and CP decreased, but no significant difference was observed $(\mathrm{P}>0.05)$.

SIP attenuates the destruction of the ultra-structure of testicular germ cells caused by CP. As shown in Fig. 4, spermatogonia and Sertoli cells in control mice were healthy, as indicated by their large nuclei, homogeneous electron density in the nucleoplasm and prominent nucleoli. Additionally, the cytoplasm of spermatogonia and Sertoli cells contained rod-shaped mitochondria with substantial cristae. However, following treatment with $\mathrm{CP}$ alone, spermatogonia nuclei 
A
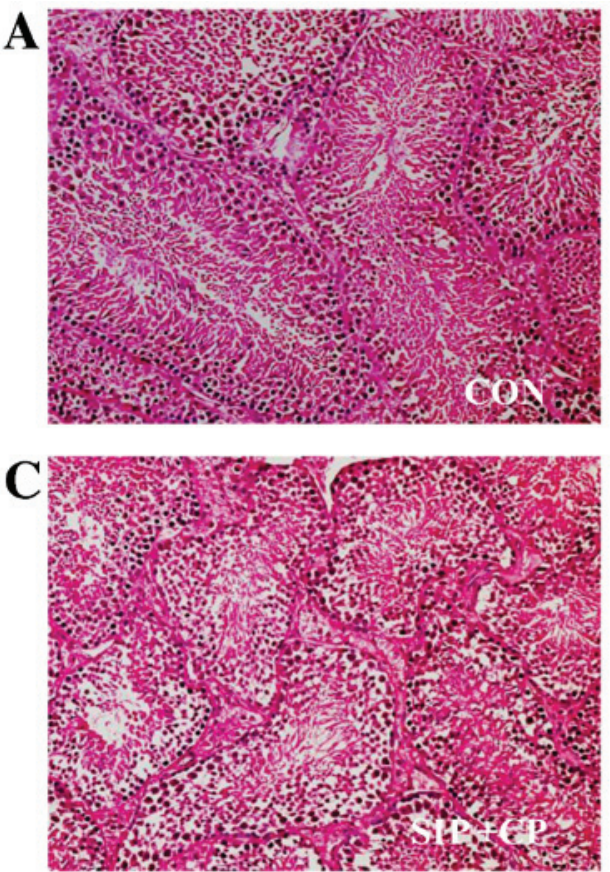
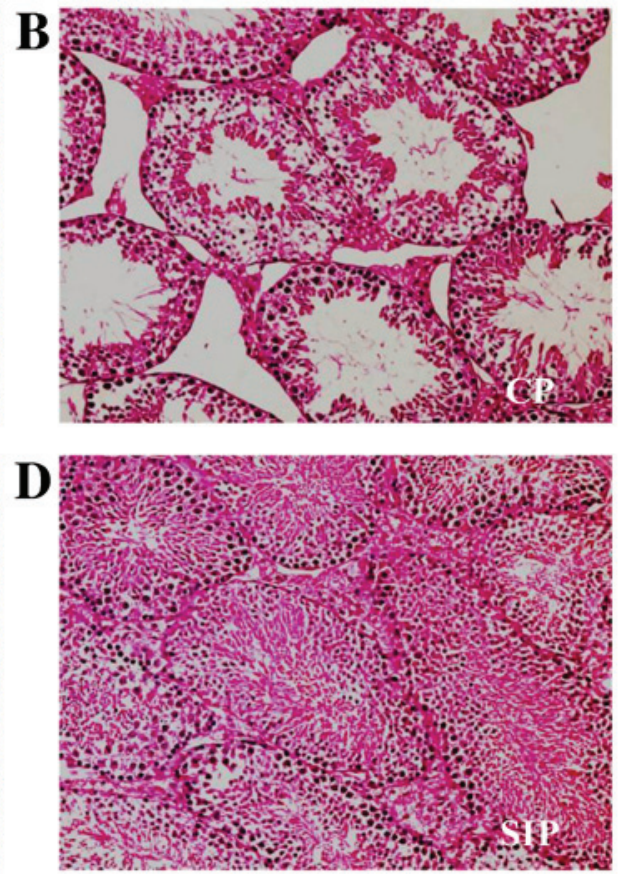

Figure 1. Histopathological observation of testicular seminiferous tubules in (A) control, (B) cp-treated, (C) SIP+CP treated and (D) SIP-treated mice.. Testicular seminiferous tubules were observed by optical microscopy and hematoxylin and eosin staining techniques. Images were captured at a magnification of x200. CON, control mice; CP, CP-treated mice; SIP+CP, mice treated with squid ink polysaccharide and CP; SIP, squid ink polysaccharide-treated mice. Scale bar $0.05 \mathrm{~mm}$.
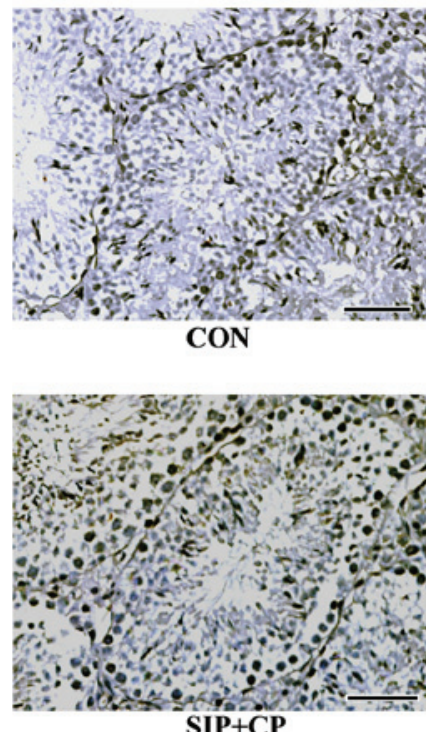
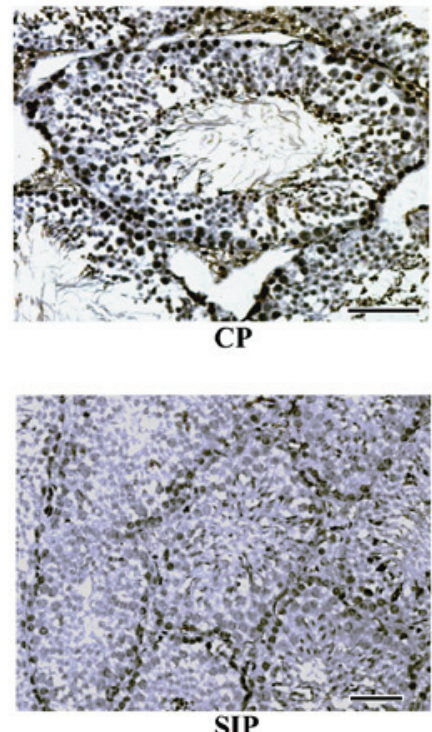

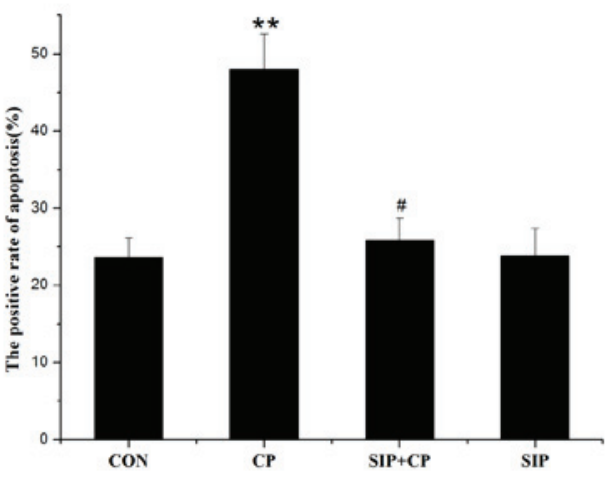

Figure 2. SIP prevents CP-induced apoptosis of testicular germ cells. Testicular seminiferous tubules was observed by optical microscopy and TUNEL techniques, images were captured at a magnification of $x 400$. " $\mathrm{P}<0.01$ vs. CON. ${ }^{*} \mathrm{P}<0.05$ vs. CP. Scale bar $0.05 \mathrm{~mm}$. CON, control mice CP, CP-treated mice; $\mathrm{SIP}+\mathrm{CP}$, mice treated with squid ink polysaccharide and CP; SIP, squid ink polysaccharide-treated mice.

exhibited chromatorrhexis and chromatin pyknosis, and Sertoli cells appeared to undergo chromatin margination. Moreover, mitochondria in the two types of cells were swollen and displayed a lack of cristae. In some cases, spherical cellular monolayers were evident. Under administration of SIP and $\mathrm{CP}$, spermatogonia and Sertoli cells demonstrated improved ultrastructure, indicated by clear and evident nucleoli, the homogenous electron density of the nucleoplasm and clear cristae present in numerous mitochondria. In SIP-treated mice, nucleoli in spermatogonia and Sertoli cells were clear and obvious, the karyoplasm was light in colour and of uniform density, and the cytoplasm had many mitochondria with rich cristae.

\section{Discussion}

As a clinical chemotherapeutic agent that is widely used, CP inevitably has some negative effects on the normal tissues and 

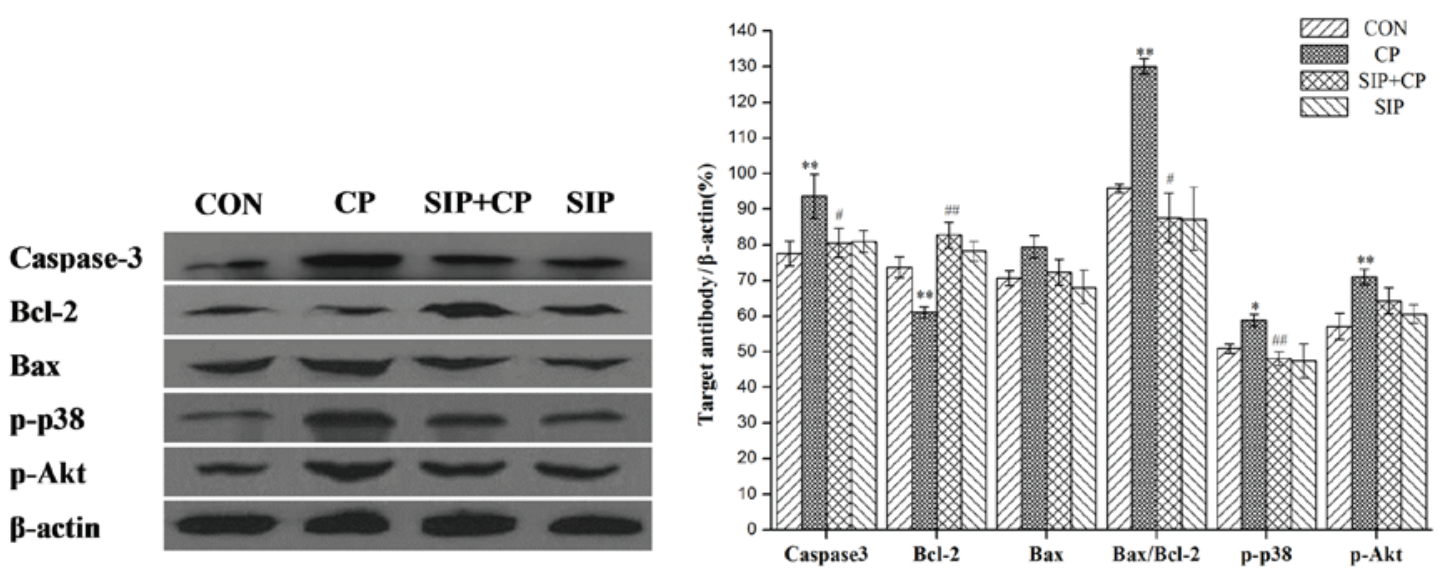

Figure 3. Effects of SIP on CP-mediated expression of Caspase-3, Bcl-2 and Bax genes, as well as phosphorylation of p38 and Akt proteins. ${ }^{*} \mathrm{P}<0.05$, ${ }^{* *} \mathrm{P}<0.01$ vs. CON. ${ }^{~} \mathrm{P}<0.05,{ }^{\# \prime} \mathrm{P}<0.01$ vs. CP. CON, control mice; $\mathrm{CP}, \mathrm{CP}$-treated mice; SIP+CP, mice treated with squid ink polysaccharide and $\mathrm{CP}$; SIP, squid ink polysaccharide-treated mice; p-, phosphorylated; Akt, AKT serine/threonine kinase; Bcl-2, B-cell lymphoma 2; Bax, Bcl-2-associated X protein.

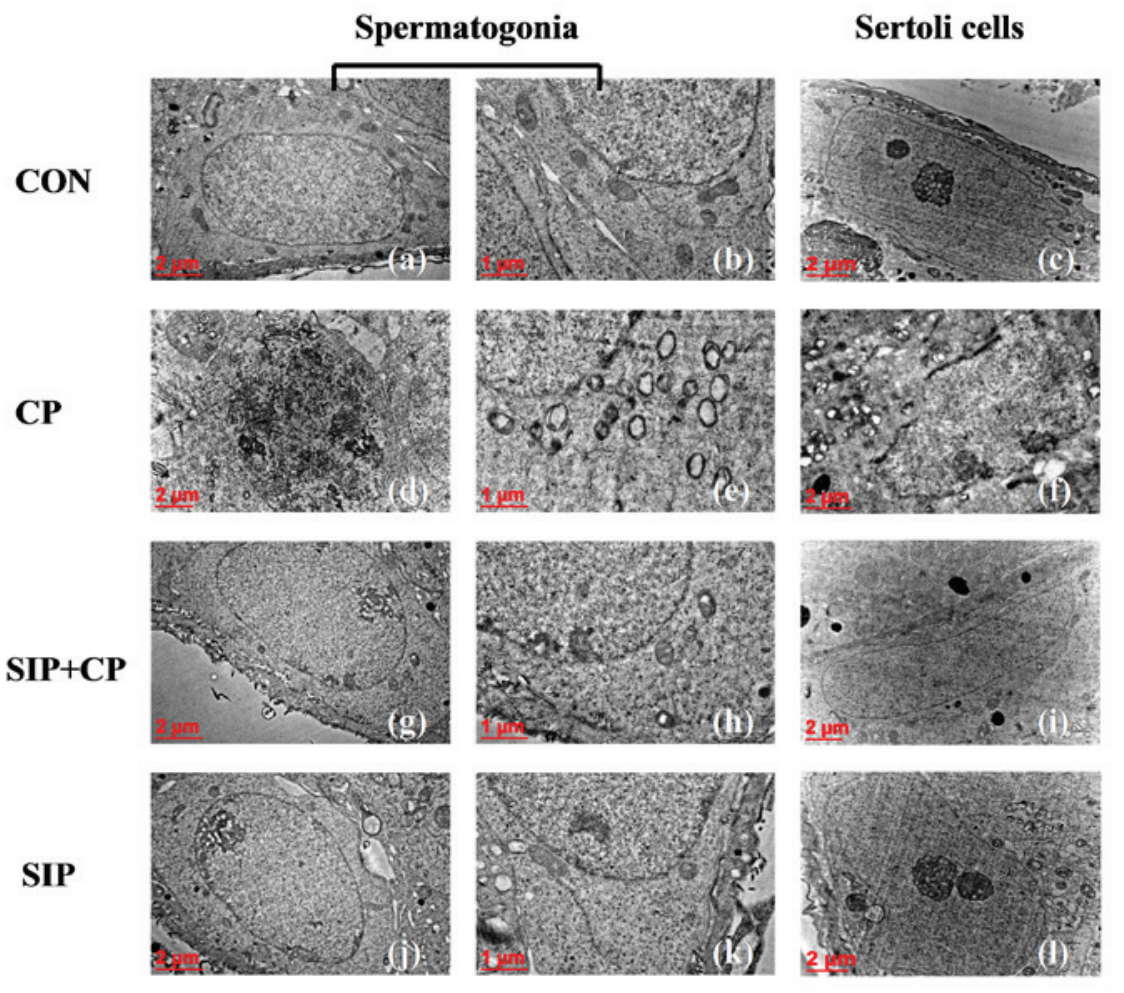

Figure 4. Ultrastructure of testicular spermatogonia and Sertoli cells in four groups of mice as assessed by transmission electron microscopy. Images were obtained at magnifications of x12,000 (c, f, i, l), x15,000 (a, d, g, j), x30,000 (b, e, h, k). CON, control mice; CP, CP-treated mice; SIP+CP, mice treated with squid ink polysaccharide and CP; SIP, squid ink polysaccharide-treated mice.

organs of patients with cancer, such as infertility or genetic toxicity $(23,24)$. Two main physiological functions of testes is the generation of sperm and endocrine regulation, the latter restricts the former through they interact with each other $(25,26)$. Apoptosis within seminiferous tubules is necessary to maintain a dynamic equilibrium in the testes and the generation of healthy sperm. However, chemotherapeutic drugs, such as CP, may generate excess free radicals and oxidation products and weaken testicular antioxidant functions, which may destroy the oxidation-antioxidation balance system in testes and result in testicular oxidative stress $(27,28)$. Oxidative stress-induced accumulation of ROS may result in serious damage to mitochondria, including DNA mutation, lipid peroxidation and mitochondrial membrane channel opening, which leads to reduced mitochondrial function and male reproductive disorder (29). In the present study, CP induced injury to testis in male mice, including excessive ROS and MDA, decreased SOD activity and number of germ cells, as well as hollowed seminiferous tubules. Moreover, nuclear fragmentation and condensation, enlarged mitochondria and reduced cristae were 
observed in spermatogonial cells and Sertoli cells, the number of apoptosis-positive cells was elevated and these apoptotic cells were predominantly distributed in spermatogonial cell layers. These data support the CP-induced theory of oxidative stress $(1,20)$. Additionally, mitochondria are organelles that are highly sensitive to stressful stimulations, oxidative stress alters mitochondrial membrane permeability and potential, which leads to mitochondrial swelling (29). In the present study, mitochondria were swollen and displayed a lack of cristae in spermatogonial cells and Sertoli cells. Therefore, cristae are important structures involved in mitochondrial energy metabolism, and their destruction inevitably causes mitochondrial energy metabolism disorder (30). Thus, based on the results of the current study, there was an association between oxidative stress and the apoptosis in cells, with low activities of antioxidative enzymes, nuclear pyknosis, mitochondrial swelling and vesiculation.

The marine polysaccharide, SIP, has demonstrated strong antioxidant capacity and it is able to effectively weaken the toxicity of $\mathrm{CP}$ on the male reproductive system (1). The present findings, demonstrated that SIP inhibited apoptosis of germ cells via improving antioxidant ability by hindering oxidative damage in mitochondria and suppressing activation of Caspase-3 protein in CP-exposed mice. Furthermore, SIP depleted ROS and therefore reduced the expression levels of pro-apoptotic Bax genes in spermatogonia and Sertoli cells, allowing these cells to maintain their morphological structural integrity. As a result, the blood-testis barrier was protected and normal physiological functions in the testes were conserved.

Multiple factors of signaling pathways are involved in the inhibition of apoptosis. Anti-apoptotic protein, Bcl-2, combines with Bax to form a homodimeror heterodimer that inhibits apoptosis (31). The present study indicated that SIP increased the content of Bcl-2 and decreased the Bax/Bcl-2 ratio, which suggested that SIP inhibited CP-induced apoptosis by regulating expression levels of $\mathrm{Bcl}-2$ and Bax genes in the testes of CP-treated mice. The $\mathrm{p} 38$ mitogen-activated protein kinase (MAPK) signal transduction pathway relies on $\mathrm{p} 38$, which is an important member of the MAPK familythat can be activated by anti-tumor drugs or ROS; p38 has been used to inhibit tumors by inducing tumor cells apoptosis (32). The present results suggested that $\mathrm{CP}$-activated $\mathrm{p} 38$ protein was dephosphorylated by SIP, or that SIP suppressed the phosphorylation of $\mathrm{p} 38$ protein induced by $\mathrm{CP}$, which indicated that SIP may impair p38 activation by scavenging CP-mediated ROS to depress apoptosis. Akt is an important target kinase in the downstream actions of phosphatidylinositol-2-kinase, its phosphorylation can activate or inhibit downstream target proteins such as Bad, Caspase-9, nuclear factor kappa B and prostate apoptosis response-4 to block apoptosis (33-36). Akt signaling is considered to be an important mechanism that contributes toward sapoptosis inhibition $(37,38)$. In the present study, it was identified that $\mathrm{CP}$ upregulated the content of phospho-Akt and the level of Akt phosphorylation was not significantly reduced after inhibition of apoptosisby SIP. We speculate that SIP may improve the cellular environmental impact of $\mathrm{CP}$ and contribute to Akt-mediated inhibition of apoptosis.

In conclusion, SIP weakened CP-induced oxidative stress to improve the antioxidant ability, protected functions of mitochondria, increased expression levels of Bcl-2 and reduced expression levels of Caspase-3 and Bax. Furthermore, SIP inhibited the p38 MAPK signal pathway, thus suppressing CP-induced apoptosis in testicular germ cells.

\section{Acknowledgements}

This study was supported by the National Natural Science Foundation of China (grant no. 31171667), the Special Fund for Distinguished Experts in Guangxi and the Guangxi Talent Highland of Preservation and Deep Processing Research in Fruit and Vegetables.

\section{References}

1. Le XY, Luo P, Gu YP, Tao YX and Liu HZ: Interventional effects of squid ink polysaccharides on cyclophosphamide-associated testicular damage in mice. Bratisl Lek Listy 116: 334-339, 2015.

2. Mythili Y, Sudharsan PT, Selvakumar E and Varalakshmi P: Protective effect of DL-alpha-lipoic acid on cyclophosphamide induced oxidative cardiac injury. Chem Biol Interact 151: 13-19, 2004.

3. Aguilar-Mahecha A,Hales B and Robaire B: Effects of acute and chronic cyclophosphamide treatment on meiotic progression and the induction of DNA double-strand breaks in rat spermatocytes. Biol Reprod 72: 1297-1304, 2005.

4. Zhang J, Ma K and Wang H: Cyclophosphamide suppresses thioredoxin reductase in bladder tissue and its adaptive response via inductions of thioredoxin reductase and gluththione peroxidase. Chem Biol Interact 162: 24-30, 2006.

5. Faleiro L and Lazebnik Y: Caspases disrupt the nuclear-cytoplasmic barrier. J Cell Biol 151: 951-959, 2000.

6. Wu Z, Wu L, Li L, Tashiro S, Onodera S and Ikejima T: p53-mediated cell cycle arrest and apoptosis induced by shikonin via a caspase-9-dependent mechanism in human malignant melanoma A375-S2 cells. J Pharmacol Sci 94: 166-176, 2004

7. Maiuri MC, Tasdemir E, Criollo A, Morselli E, Vicencio JM, Carnuccio R and Kroemer G: Control of autophagy by oncogenes and tumor suppressor genes. Cell Death Differ 16: 87-93, 2009.

8. Simon HU, Haj-Yehia A and Levi-Schaffer F: Role of reactive oxygen species (ROS) in apoptosis induction. Apoptosis 5: 415-418, 2000.

9. Zhang Y, Zhang X, Rabbani ZN, Jackson IL and Vujaskovic Z: Oxidative stress mediates radiation lung injury by inducing apoptosis. Int J Radiat Oncol Biol Phys 83: 740-748, 2012.

10. Cai L, Hales BF and Robaire B: Induction of apoptosis in the germ cells of adult male rats after exposure to cyclophosphamide. Biol Reprod 56: 1490-1497, 1997.

11. Zong A, Zhao T, Zhang Y, Song X, Shi Y, Cao H, Liu C, Cheng Y, Qu X, Cao J and Wang F: Anti-metastatic and anti-angiogenic activities of sulfated polysaccharide of Sepiella maindroni ink. Carbohyd Polym 91: 403-409, 2013.

12. Zuo T, He X, Cao L, Xue C and Tang QJ: The dietary polysaccharide from Ommastrephes bartrami prevents chemotherapeutic mucositis by promoting the gene expression of antimicrobial peptides in Paneth cells. J Funct Foods 12: 530-539, 2015.

13. Zuo T, Cao L, Xue C and Tang QJ: Dietary squid ink polysaccharide induced goblet cells to protect small intestine from chemotherapy induced injury. Food Funct 6: 981-986, 2015.

14. Tang Q, Zuo T, Lu S, Wu J, Wang J, Zheng R, Chen S and Xue C: Dietary squid ink polysaccharides ameliorated the intestinal microflora dysfunction in mice undergoing chemotherapy. Food Funct 5: 2529-2535, 2014

15. Zuo T, Cao L, Li X, Zhang Q, Xue C and Tang QJ: The squid ink polysaccharides protect tight junctions and adherens junctions from chemotherapeutic injury in the small intestinal epithelium of mice. Nutr Cancer 67: 364-371, 2015.

16. Zuo T, Cao L, Sun X, Li X, Wu J, Lu S, Xue C and Tang Q: Dietary squid ink polysaccharide could enhance SIgA secretion in chemotherapeutic mice. Food Funct 5: 3189-3196, 2014.

17. Chen S, Xu J, Xue C, Dong P, Sheng W, Yu G and Chai W: Sequence determination of a non-sulfated glycosaminoglycan-like polysaccharide from melanin-free ink of the squid Ommastrephes bartrami by negative-ion electrospray tandem mass spectrometry and NMR spectroscopy. Glycoconj J 25: 481-492, 2008 
18. Liu HZ, Wang G, Wu JL, Shi LS, Zhong JP and Pan JQ Amelioratory effects of squid ink polysaccharides on partial internal organs injuried by cyclophosphamide. Chinese J Mod Appl Pharm 2: 89-93, 2012

19. Staub AM: Removal of protein-Sevag method. Methods Carbohydrate Chem 5: 5-6, 1965.

20. Le X, Luo P, Gu Y, Tao Y and Liu H: Squid ink polysaccharides reduces cyclophosphamide-induced testicular damage via Nrf2/ARE activation pathway in mice. Iran J Basic Med Sci 18: $827-831,2015$.

21. Elangovan N, Chiou TJ, Tzeng WFand Chu ST: Cyclophosphamide treatment causes impairment of sperm and its fertilizing ability in mice. Toxicology 222: 60-70, 2006.

22. Brodsky RA: High-dose cyclophosphamide for autoimmunity and alloimmunity. Immunol Res 47: 179-184, 2010.

23. Motoyoshi Y, Kaminoda K, Saitoh O, Hamasaki K, Nakao K, Ishii N, Nagayama Y and Eguchi K: Different mechanisms for anti-tumor effects of low- and high-dose cyclophosphamide. Oncol Rep 16: 141-146, 2006.

24. Guittin P, Labbe V, Cavalier JC, Delongeas JL and Hodge T: Effects of cyclophosphamide administration on different fertility evaluation tests in male rats. Teratology 53: 30A, 1996.

25. Luboshitzky R, Shen-Orr Z and Herer P: Seminal plasma melatonin and gonadal steroids concentrations in normal men. Arch Androl 48: 225-232, 2002.

26. Martin CW, Riley SC, Everington D, Groome NP, Riemersma RA, Baird DT and Anderson RA: Dose-finding study of oral desogestrel with testosterone pellets for suppression of the pituitary-testicular axis in normal men. Hum Reprod 15: 1515-1524, 2000.

27. Iuchi Y, Kaneko T, Matsuki S, Ishii T, Ikeda Y, Uchida K and Fujii J: Carbonyl stress and detoxification ability in the male genital tract and testis of rats. Histochem Cell Biol 121: 123-130, 2004.

28. Selvakumar E, Prahalathan C, Sudharsan PT and Varalakshmi P: Protective effect of lipoic acid on cyclophosphamide-induced testicular toxicity. Clin Chim Acta 367: $114-119,2006$
29. Motawi TM, Sadik NA and Refaat A: Cytoprotective effects of DL-alpha-lipoic acid or squalene on cyclophosphamide-induced oxidative injury: An experimental study on rat myocardium, testicles and urinary bladder. Food Chem Toxicol 48: 2326-2336, 2010.

30. Tinari A, Garofalo T, Sorice M, Esposti MD and Malorni W: Mitoptosis: Different pathways for mitochondrial execution. Autophagy 3: 282-284, 2007.

31. Lindsay J,Esposti MD and Gilmore AP: Bcl-2 proteins and mitochondria-specificity in membrane targeting for death. Biochim Biophys Acta 1813: 532-539, 2011.

32. Xie N, Li H, Wei D, LeSaga G, Chen L, Wang S, Zhang Y, Chi L, Ferslew K, He L, et al: Glycogen synthase kinase-3 and p38 MAPK are required for opioid-induced microglia apoptosis. Neuropharmacology 59: 444-451, 2010.

33. Cardone MH, Roy N, Stennicke HR, Salvesen GS, Franke TF, Stanbridge E, Frisch S and Reed JC: Regulation of cell death protease caspase-9 by phosphorylation. Science 282: 1318-1321, 1998.

34. Niquet J and Wasterlain CG: Bim, Bad, and Bax: A deadly combination in epileptic seizures. J Clin Invest 113: 960-962, 2004.

35. Jeong SJ, Pise-Masison CA, Radonovich MF, Park HU and Brady JN: Activated AKT regulates NF-kappaB activation, p53 inhibition and cell survival in HTLV-1-transformed cells. Oncogene 24: 6719-6728, 2005.

36. Goswami A, Burikhanov R, de Thonel A, Fujita N, Goswami M, Zhao Y, Eriksson JE, Tsuruo T and Rangnekar VM: Binding and phosphorylation of par-4 by akt is essential for cancer cell survival. Mol Cell 20: 33-44, 2005.

37. Dan HC, Sun M, Kaneko S, Feldman RI, Nicosia SV, Wang HG, Tsang BK and Cheng JQ: Akt phosphorylation and stabilization of X-linked inhibitor of apoptosis protein (XIAP). J Biol Chem 291: 22846, 2016.

38. Chang F, Lee JT, Navolanic PN, Steelman LS, Shelton JG, Blalock WL, Franklin RA and McCubrey JA: Involvement of PI3K/Akt pathway in cell cycle progression, apoptosis, and neoplastic transformation: A target for cancer chemotherapy. Leukemia 17: 590-603, 2003. 